Article

\title{
Bismuth Oxide Faceted Structures as a Photocatalyst Produced Using an Atmospheric Pressure Plasma Jet
}

\author{
Robert Köhler ${ }^{1, * \mathbb{C}}$, Dominik Siebert ${ }^{1}$, Leif Kochanneck ${ }^{2}$, Gisela Ohms ${ }^{1}$ and Wolfgang Viöl ${ }^{1}$ [D \\ 1 Laboratory of Laser and Plasma Technologies, University of Applied Sciences and Arts, Von-Ossietzky-Str. \\ 99, 37085 Göttingen, Germany; dominik.siebert@hawk.de (D.S.); gisela.ohms@hawk.de (G.O.); \\ wolfgang.vioel@hawk.de (W.V.) \\ 2 Institute of Materials Physics, Georg-August-Universität Göttingen, 37077 Göttingen, Germany; \\ leif.kochanneck@outlook.de \\ * Correspondence: robert.koehler@hawk.de; Tel.: +49-551-3705-212
}

Received: 5 June 2019; Accepted: 12 June 2019; Published: 14 June 2019

\begin{abstract}
The photocatalyst bismuth oxide, which is active under visual light, was deposited using an atmospheric pressure plasma jet (APPJ). Sixteen different samples were generated under different parameters of the APPJ to investigate their catalytic activity. The prepared samples were characterized using X-ray diffraction (XRD), X-ray photoelectron spectroscopy (XPS), laser scanning microscopy (LSM), and UV-vis diffuse reflectance absorption spectroscopy. The measured data, such as average sample thickness, coverage ratio, phase fraction, chemical composition, band gap, and photocatalytic performance were used for comparing the samples. The XRD analysis showed that the deposition process produced a mixed phase of monocline $\mathrm{Bi}_{2} \mathrm{O}_{3}$ and tetragonal $\mathrm{Bi}_{2} \mathrm{O}_{2.33}$. Using the Rietveld refinement method, phase fractions could be determined and compared with the XPS data. The non-stoichiometric phases were influenced by the introduction of nitrogen to the surface as a result of the deposition process. The band gap calculated from the diffuse absorption spectroscopy shows that $\mathrm{Bi}_{2} \mathrm{O}_{2.33}$ with $2.78 \mathrm{eV}$ had a higher band gap compared to the phases with a high proportion of $\mathrm{Bi}_{2} \mathrm{O}_{3}(2.64 \mathrm{eV})$. Furthermore, it was shown that the band gap was dependent on the thickness of the sample and oxygen vacancies or loss of oxygen in the surface. All coatings had degraded methyl orange (MO) under irradiation by xenon lamps.
\end{abstract}

Keywords: bismuth oxide; atmospheric pressure plasma; methyl orange; spectroscopy

\section{Introduction}

The two main objectives of semiconductor photocatalysts are the photolysis of water for storing energy in chemical bonds, for example in the form of hydrogen and oxygen, and the catalytic degradation of pollutants [1]. In addition to the well-known photocatalysts, such as titanium or zinc oxide, bismuth oxide is becoming increasingly important. Bismuth oxide is a polymorphic oxide with six different crystal phases [2,3]. In addition to the stoichiometric phases, non-stoichiometric phases, such as $\mathrm{Bi}_{2} \mathrm{O}_{2.33}$, are also known [4]. All phases have different crystal structures and various optical, electrical, and mechanical properties [5], which are all important for the practical application of a photocatalyst. However, certain phases of this semiconductor, as reported in the literature, are characterized by desirable properties such as a narrow energy band gap [6], high refractive index [7], and photoconductivity and photoluminescence properties [8].

The high band gap of bismuth oxide allows for the generation of electron-hole pairs if the photocatalyst is irradiated with photons of higher photon energy. This can lead to the formation of free radicals that promote chemical reactions to break down pollutants from the environment [9]. It has 
been shown that bismuth oxides can be used for the degradation of model pollutants, like methyl orange (MO) [10], methylene blue [11], or rhodamine B [12].

In general, the photocatalytic performance depends on the physicochemical properties of the metal oxide [13]. The crystal structure, morphology, and microstructure, as well as the phase fractions and chemical composition, play key roles [14,15]. An atmospheric pressure plasma jet (APPJ) was chosen because it allows these parameters to be modified, making it possible to study the influence on the catalytic effect.

Previous research has shown that an APPJ system can be used to generate crystalline bismuth oxide samples. The generation of crystalline phases using a plasma jet was confirmed and a mixed phase of stoichiometric and non-stoichiometric bismuth oxide was generated [16].

The influence and given correlations of layer thickness, cover ratio, phase fraction, chemical composition, band gap, and photocatalytic performance of different coatings produced using an APPJ are presented in this publication. The process parameters that have an influence on the measured quantities will be presented in a future publication.

\section{Results and Discussion}

\subsection{Average Thickness and Cover Ratio}

In order to determine the surface characteristics of the bismuth oxide coatings, laser scanning microscopy (LSM) measurements were carried out. As shown in Köhler et al. [16], the bismuth oxide particles melted in the plasma torch and formed lenticular structures on impact with the substrate surface. In layers with a higher degree of coverage, the structures overlap and a kind of lamellar structure is formed [17]. The layer thus created can be described as a faceted structure (FS). The average thickness of the FS was $0.16-2.4 \mu \mathrm{m}$ and the degree of coverage was $19.3-98.5 \%$ (see Figure 1a,b).
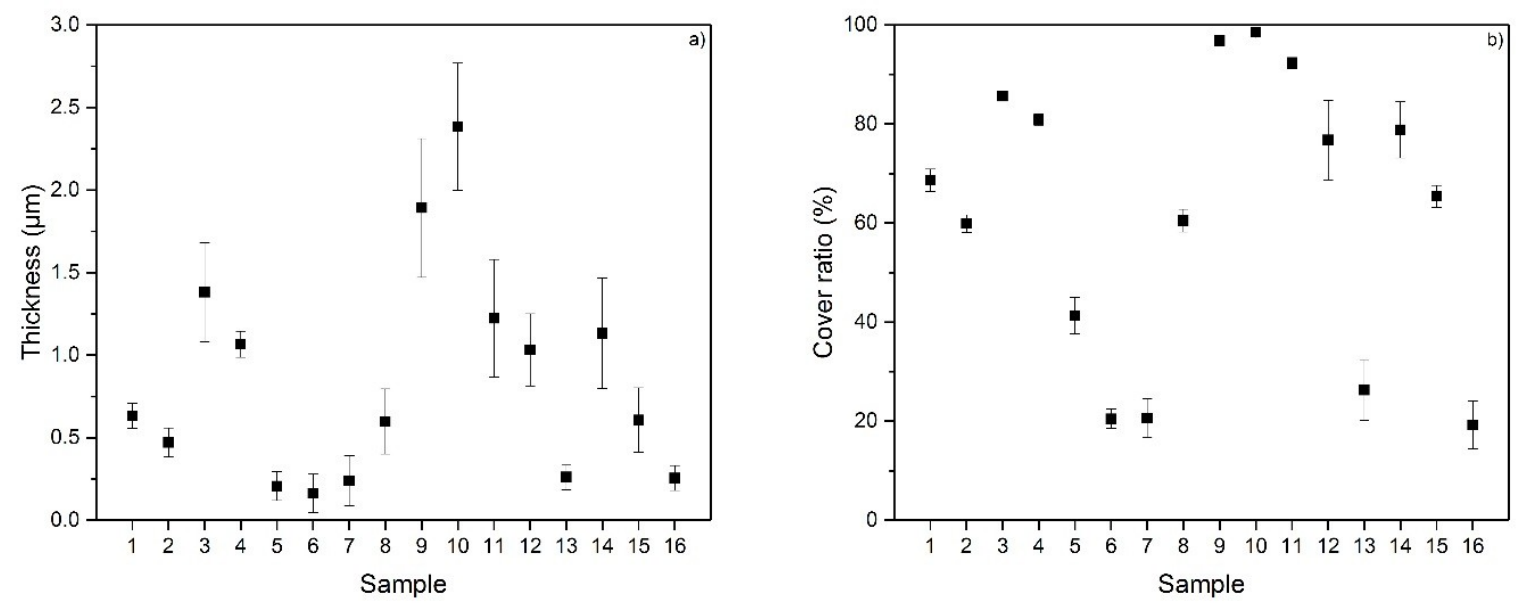

Figure 1. Average thickness (a) and cover ratio (b) of the FSs (N=4 and SD).

\subsection{X-ray Diffraction (XRD)}

XRD measurements were conducted to evaluate the crystal structures of the coatings. Figure 2 shows the XRD patterns normalized to the respective main reflex in a range of $35-50^{\circ}$. The deposited layers showed two kinds of crystal structures: the non-stoichiometric $\mathrm{Bi}_{2} \mathrm{O}_{2.33}$ (PDF-Nr.: 00-027-0051) and monoclinic bismuth oxide (PDF-Nr.: 03-065-2366). The main reflex of non-stoichiometric $\mathrm{Bi}_{2} \mathrm{O}_{2.33}$ was detected at $43.8^{\circ}(107)$. The reflexes at $41.3^{\circ}(120)$ and $42.2^{\circ}(012)$ were assigned to the monoclinic phase. The Rietveld refinement method was used to determine the phase fractions of the deposited layer. The results are shown in Figure 2. All samples contained a proportion of non-stoichiometric $\mathrm{Bi}_{2} \mathrm{O}_{2.33}$; this may be due to the coating process. The tetragonal non-stoichiometric bismuth oxide 
phase was able to be generated by bulk crystal defects [18] or interstitials defects [19] during the deposition process.
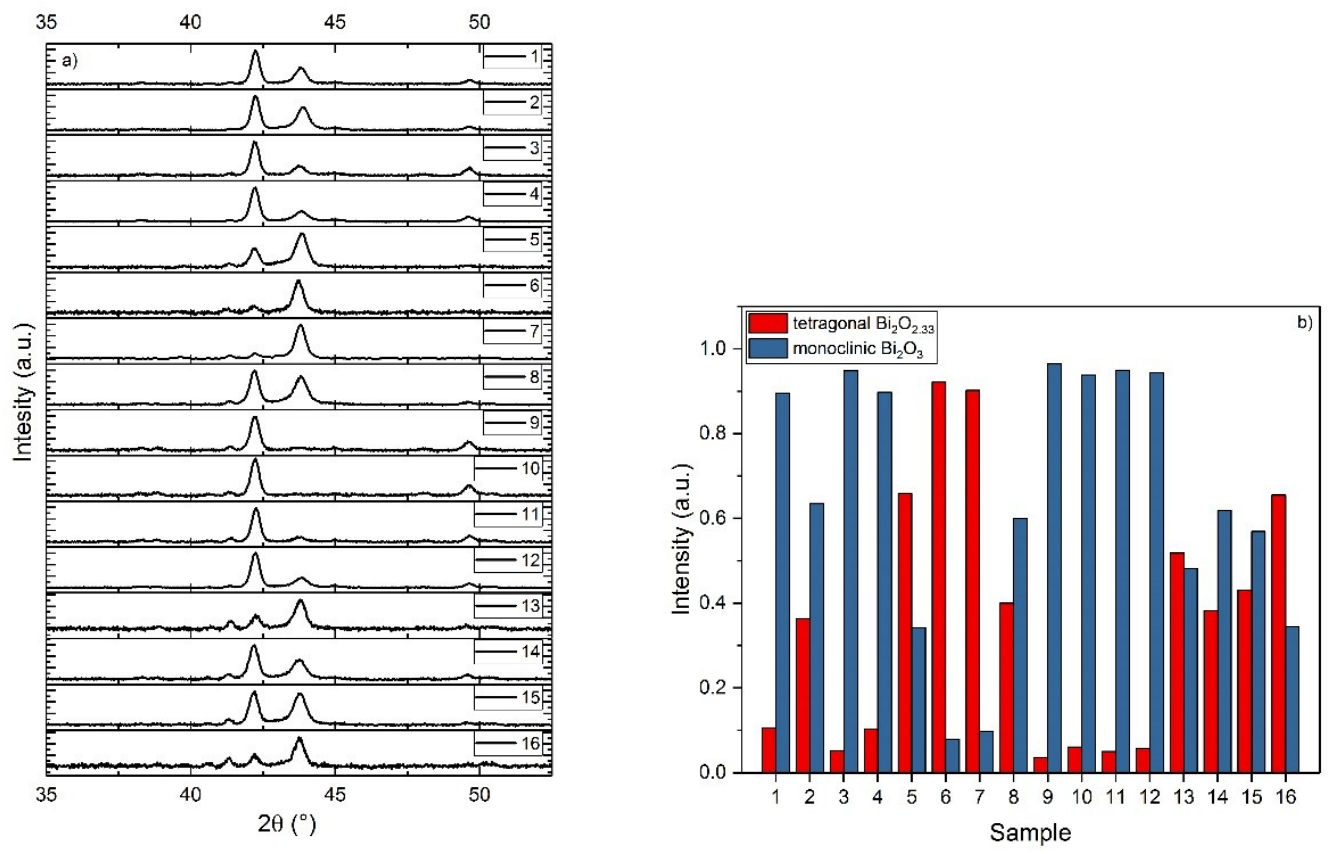

Figure 2. (a) Normalized XRD plot of parameter set and (b) phase fraction of layers with tetragonal non-stoichiometric $\mathrm{Bi}_{2} \mathrm{O}_{2.33}$ and monoclinic $\mathrm{Bi}_{2} \mathrm{O}_{3}$.

\subsection{X-ray Photoelectron Spectroscopy (XPS)}

The FS surfaces were also investigated using XPS measurements in order to determine the elemental composition and binding states. The spectra consisted of four elements: bismuth, oxygen, nitrogen, and carbon; depending on the coverage of the layer, silicon was detected from the substrate. The atomic concentrations are shown in Table 1.

Table 1. Atomic concentration of the FS in atom- $\%$.

\begin{tabular}{cccccc}
\hline Sample & $\mathbf{C} \mathbf{1 s}$ & $\mathbf{N} \mathbf{1 s}$ & $\mathbf{O} \mathbf{1 s}$ & $\mathbf{S i} \mathbf{p}$ & $\mathbf{B i} \mathbf{f}$ \\
\hline 1 & 29.6 & 1.3 & 43.0 & 3.2 & 23.0 \\
2 & 22.5 & 1.3 & 48.9 & 3.0 & 24.3 \\
3 & 32.6 & 1.6 & 42.1 & 0.0 & 23.7 \\
4 & 20.9 & 1.8 & 51.0 & 6.5 & 19.8 \\
5 & 16.7 & 2.4 & 53.2 & 4.8 & 22.9 \\
6 & 22.4 & 5.0 & 49.9 & 1.8 & 20.9 \\
7 & 22.3 & 4.1 & 49.3 & 4.3 & 20.1 \\
8 & 23.4 & 3.7 & 46.9 & 0.7 & 25.3 \\
9 & 24.1 & 2.4 & 47.5 & 0.0 & 25.9 \\
10 & 25.4 & 0.3 & 46.2 & 0.0 & 28.1 \\
11 & 27.0 & 0.8 & 43.7 & 1.4 & 27.2 \\
12 & 21.5 & 1.2 & 47.1 & 0.6 & 29.7 \\
13 & 27.8 & 2.5 & 45.8 & 2.1 & 22.0 \\
14 & 26.9 & 1.9 & 45.6 & 0.5 & 25.1 \\
15 & 26.7 & 1.8 & 45.4 & 2.8 & 23.3 \\
16 & 28.1 & 1.9 & 45.2 & 5.2 & 19.7 \\
\hline
\end{tabular}

For an exemplary representation, the detailed spectra of oxygen, bismuth, and nitrogen of one FS with a high amount of $\mathrm{Bi}_{2} \mathrm{O}_{2.33}, \mathrm{Bi}_{2} \mathrm{O}_{3}$, and a mix of both are compared to each other in Figure 3 . 

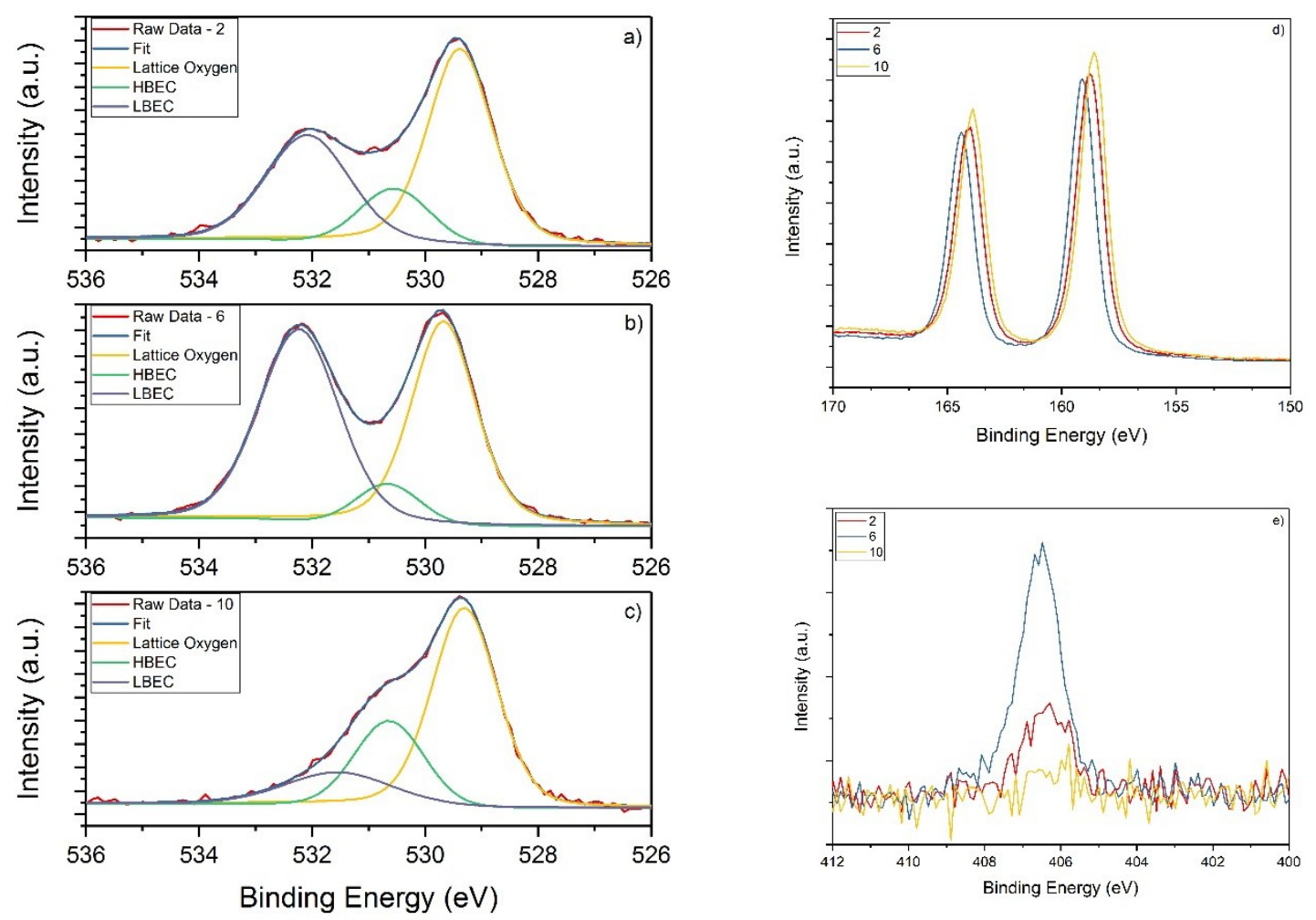

Figure 3. Detailed XPS spectra of (a-c) oxygen, (d) bismuth, and (e) nitrogen.

The $\mathrm{O} 1 \mathrm{~s}$ peak could be divided into three structures and is shown in Figure 3a-c. The main peak at $529.2-529.7 \mathrm{eV}$ with a full width at half maximum (FWHM) of 1.4 could be attributed to lattice oxygen [20]. The second structure at $530.6 \mathrm{eV}$ (FWHM 1.3) could be attributed to a high binding energy component (HBEC) developed by the increasing loss of oxygen or creation of oxygen vacancies, in comparison to the literature [21-23]. The peak at $532.7 \mathrm{eV}$ (FWHM 1.9) could be assigned to a low binding energy component (LBEC) [22] like $\mathrm{OH}^{-}$species [24]; physisorbed water [25]; nitrate groups [26]; and in the case of a non-closed $\mathrm{FS}$, to $\mathrm{SiO}_{\mathrm{x}}$ [27].

The detailed bismuth spectra consisted of a doublet corresponding to the Bi $4 f_{7 / 2}$ and Bi $4 f_{5 / 2}$ peaks with a splitting of $5.32 \mathrm{eV}$ (Figure 3d). The binding energy values of the Bi $4 f_{7 / 2}$ were from $158.6 \mathrm{eV}$ up to $159.1 \mathrm{eV}$, which indicated a $\mathrm{Bi}^{3+}$ oxidation state [28-30].

The peak position of nitrogen at $406.5 \mathrm{eV}$ is shown in Figure 3e, which indicated the existence of highly oxidized nitrogen [26]. Liu et al. [31] describe the core level N 1s peak as a nitryl bond.

The binding energy displacement of the lattice oxygen peak and the bismuth peak could be related to the phase fraction, which is shown in Figure 4. Both displacements show a dependency on the phase fraction. An increase of the phase fraction of $\mathrm{Bi}_{2} \mathrm{O}_{2.33}$ shows a shift to higher binding energies. Cheng et al. [32] described the shift of stoichiometric bismuth oxide of the oxygen and bismuth peak as a result of the presence of different crystal structures. 

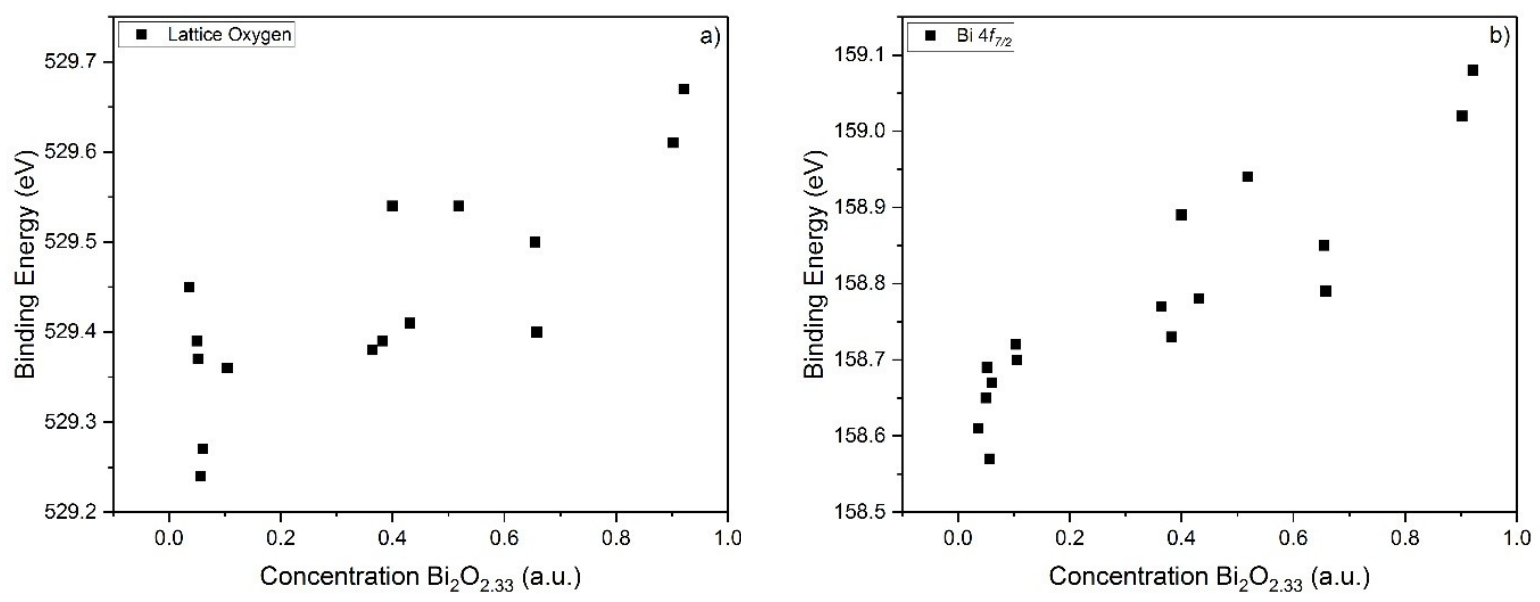

Figure 4. Peak displacement of lattice oxygen (a) and bismuth (b) depending on the phase fraction.

For a comparison of the phase fraction and the oxygen/bismuth ratio of the XPS measurement, the part of the O 1s peak of lattice oxygen and the HBEC must be added together (see Figure 5). It is shown that the $\mathrm{O} / \mathrm{Bi}$ ratio shifted from 1.5 to 1.24 with increasing non-stoichiometric phase proportions.

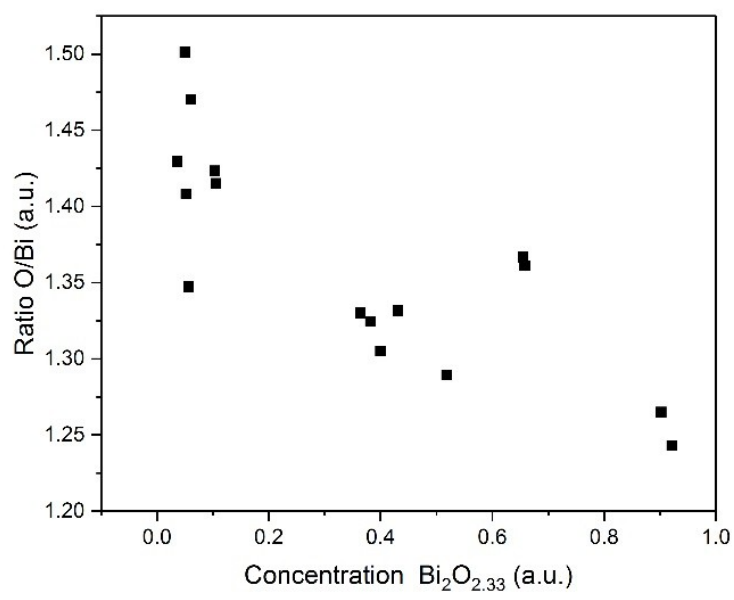

Figure 5. O/Bi ratio of XPS measurements vs. phase fraction.

The non-stoichiometry of bismuth oxide could have several reasons. Sun et al. [33] showed that non-stoichiometric bismuth oxide can occur in connection with nitrogen. Wang et al. [34] described a sintering process in which the substitution of oxygen atoms by nitrogen atoms (like metal nitride) leads to the formation of defects. Hajra et al. [35] showed the modification of oxygen-deficient bismuth oxides due to the presence of nitrogen in the metal oxide.

Figure 6 shows the $\mathrm{O} / \mathrm{Bi}$ ratio in comparison to the nitrogen, HBEC, and LBEC concentration. It can be seen that a higher proportion of nitrogen in the samples resulted in a higher proportion of non-stoichiometric bismuth oxide. This could be due to the fact that nitrogen was built into the surface, which could lead to an imbalance in the crystal phase. With an increasing concentration of $\mathrm{Bi}_{2} \mathrm{O}_{2.33}$, the HBEC concentration decreased. It could be suggested that there were more oxygen vacancies or loose oxygen in the monoclinic phase of bismuth oxide than in the tetragonal phase of non-stoichiometric bismuth oxide. The increase of LBEC in the FSs could have several reasons. Since the non-stoichiometric FSs have a lower degree of coverage than the stoichiometric FSs, the $\mathrm{SiO}_{\mathrm{x}}$ content in the samples increased. As the nitrogen was present on the surface as a nitryl group, the proportion of oxygen increased with the proportion of nitrogen. The non-stoichiometric bismuth oxide seemed to be generated by the presence of nitrogen, which could be included as an interstitial defect rather than through the presence of oxygen vacancies. 


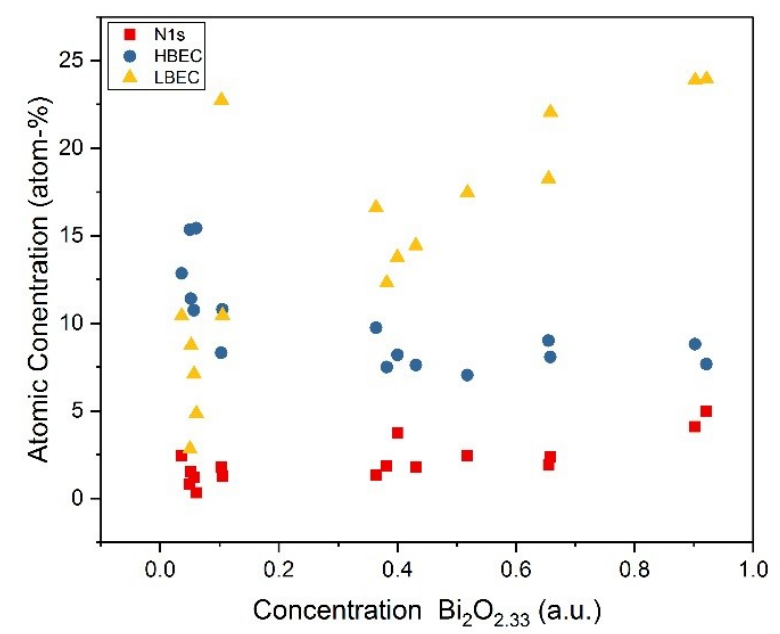

Figure 6. Phase fraction of non-stoichiometric bismuth oxide vs. atomic concentration of nitrogen, LBEC, and HBEC.

\subsection{Optical Characterization}

To calculate the energy band gap of the bismuth oxide films, the optical absorption spectra were determined at room temperature and measured using UV-vis spectroscopy. To determine the direct band gap from the absorbance, the Tauc-plot method was used with the following equation [36,37]:

$$
(\alpha h v)^{2}=A\left(h v-E_{g}\right),
$$

where $E_{g}$ is the energy of the band gap, $\alpha$ the absorption coefficient, $A$ is a constant, and $h v$ is the photon energy. The optical band gap can be determined via the extrapolation of the plot $(\alpha h v)^{2}$ versus $(h v)$, where $\alpha=0$ is set; an example is shown in Figure 7a. The band gap of the FSs ranged from $2.64 \mathrm{eV}$ up to $2.78 \mathrm{eV}$, which indicates a good visible light absorption (Figure $7 \mathrm{~b}$ ).
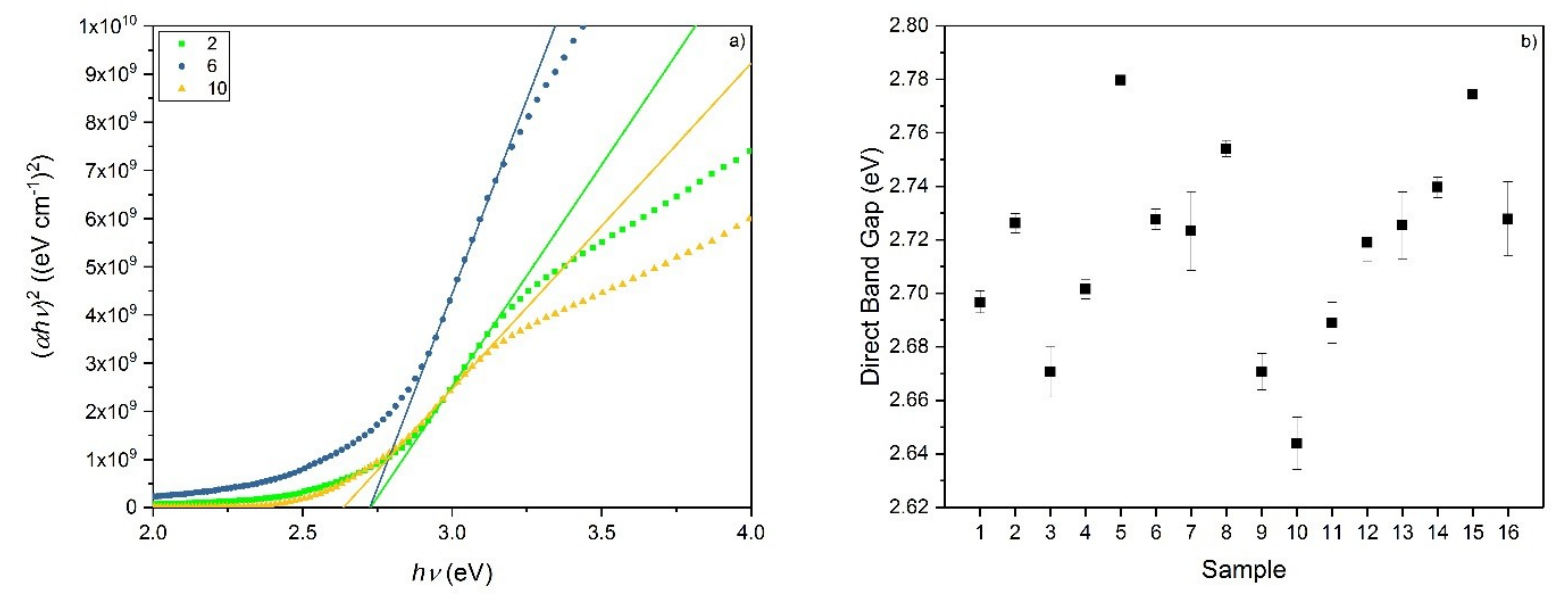

Figure 7. (a) Plot of $(\alpha h v)^{2}$ vs. (hv) to determine the direct band gap; (b) direct band gap of coatings ( $\mathrm{N}=4$ with SD).

In the literature, a shift in the band gap of bismuth oxide is described using the variation of the layer thickness, and the crystal structure and size [38-40]. Gujar et al. [41] explained that an increase in the band gap is due to changes in the crystallite size and the phase fraction of bismuth oxide. Furthermore, a reduction of defects or an increase in stoichiometric composition leads to an increase of the energy band gap [42,43]. 
Figure 8 shows the influences of the FS thickness, atomic concentration of the HBECs, and the oxygen/bismuth ratio on the band gap. The band gap decreased with an increase in HBECs and coating thickness. There was a recognizable tendency that the ratio of oxygen to bismuth also had an influence on the band gap; by reducing the ratio, the band gap rose. An influence of nitrogen on the band surface could not be determined.
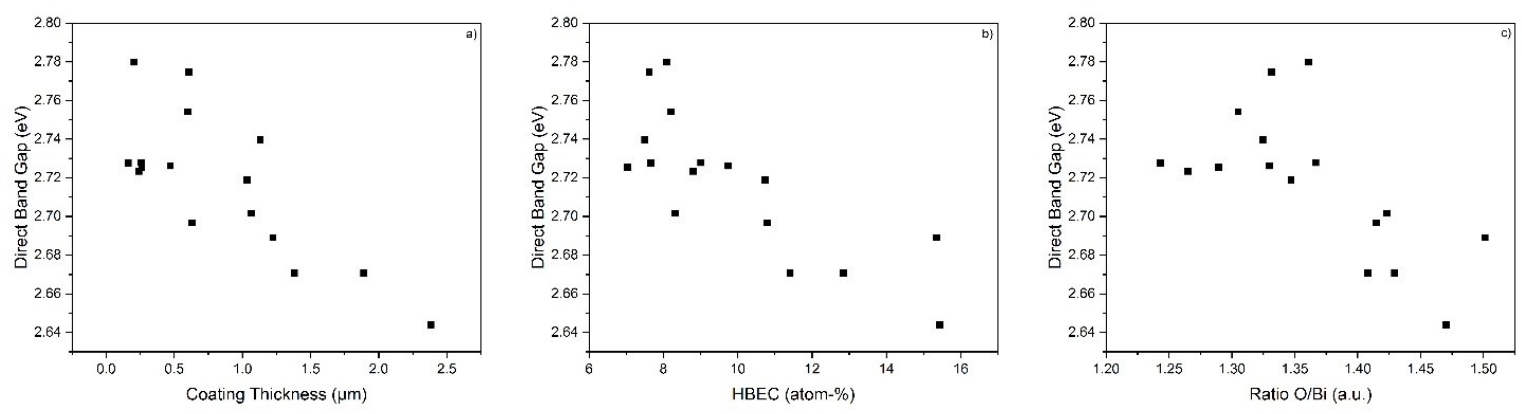

Figure 8. Direct band gap plots vs. (a) coating thickness, (b) atomic concentration of HBEC, and (c) oxygen/bismuth ratio.

\subsection{Photocatalytic Performance Test}

To determine the photocatalytic degradation efficiency of the bismuth oxide FSs, the following equation was used [44]:

$$
\text { photocatalytic efficiency }=\left(C_{0}-C_{t} / C_{0}\right) \times 100
$$

where $C_{0}$ corresponds to the initial concentration of $\mathrm{MO}$ after an initial time of $30 \mathrm{~min}$ without irradiation, and $C_{t}$ is the concentration at the illumination after time $t$. The photocatalytic degradation efficiency as a function of irradiation time is shown in Figure 9a. All degradation efficiencies of the samples after 480 min are shown in Figure $9 \mathrm{~b}$. The MO degradation rates ranged from $25.5 \%$ up to $76.7 \%$. The reference was $\mathrm{MO}$ without a catalyst, showing a degradation of $5 \%$ after the total irradiation time; it can therefore be assumed as stable under irradiation from the xenon lamps.
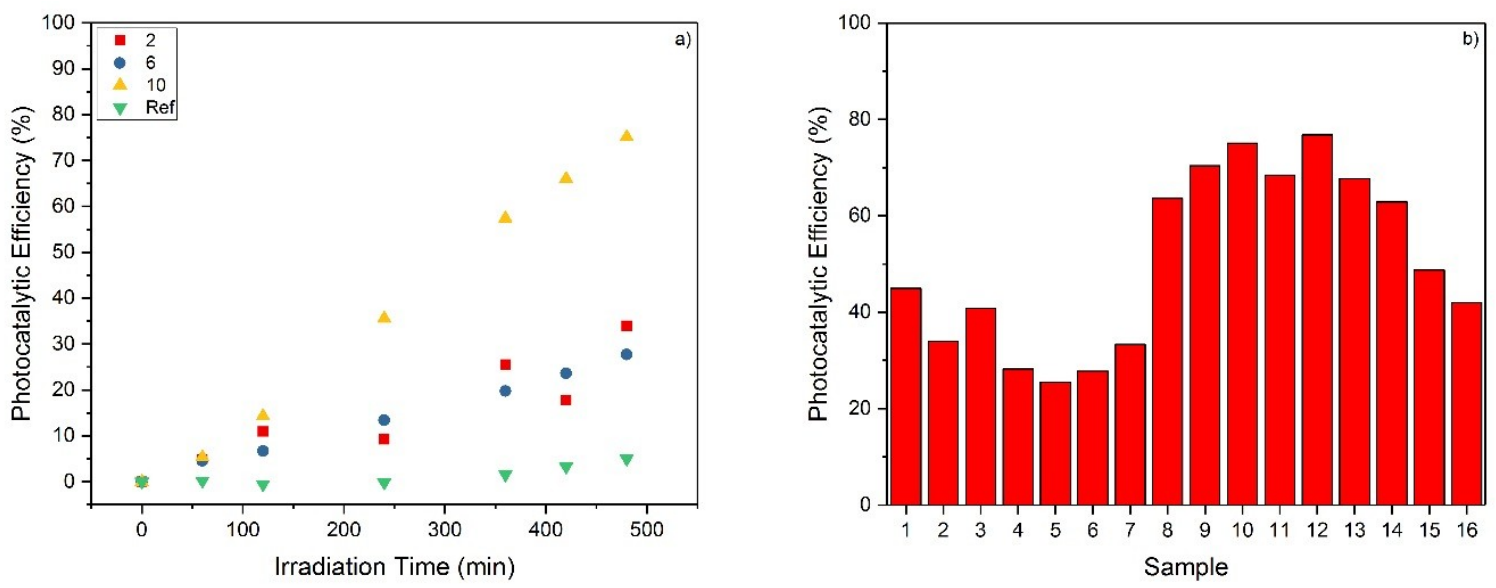

Figure 9. (a) Photocatalytic efficiency as a function of irradiation time, and (b) degradation efficiencies of coatings.

Hou et al. [45] explained that morphology, phase component, shape, and size play a role in photocatalytic efficiency. Iyyapushpam et al. [46] showed an increase of the degradation efficiency of bismuth oxide samples with a higher crystallinity. However, a direct influence of the phase fraction, band gap, or FS thickness on the degradation efficiency could not be determined. Only the chemical composition of the LBEC gave a tendency for the degradation of MO and is shown in Figure 10. 
A higher degradation rate was achieved with a lower atomic concentration of LBEC. The composition of the LBEC was assigned to $\mathrm{OH}^{-}$species, nitrate groups, physisorbed water, and partially to $\mathrm{SiO}_{x}$. This makes it more difficult to draw conclusions about the degradation performance of MO.

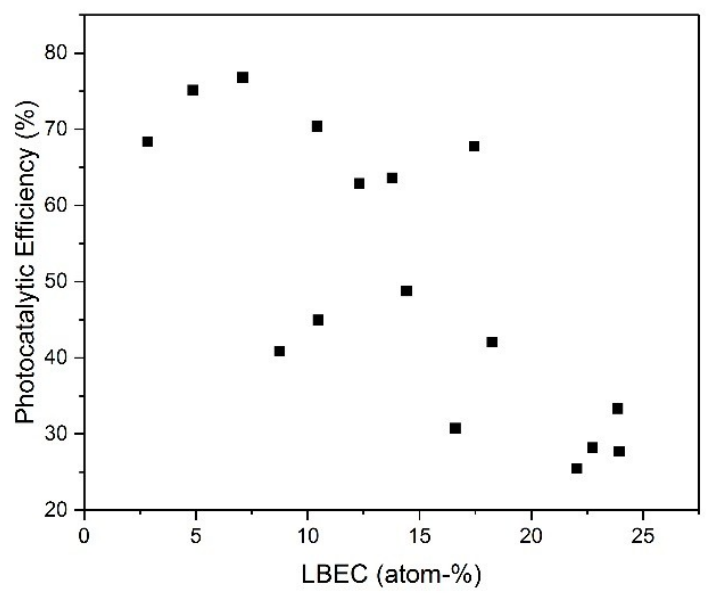

Figure 10. Atomic concentration of LBEC in atom- $\%$ vs. the photocatalytic efficiency.

In addition, the degree of coverage and the FS thickness of the substrates vary in part by an order of magnitude. This can lead to different interaction areas of the catalyst with the environment, which in turn can affect the active reaction centers. A correlation of the different factors that influence the degradation cannot be excluded.

\section{Materials and Methods}

\subsection{Coating Process}

The layers were produced by an APPJ system (Plasmadust, Reinhausen Plasma GmbH, Regensburg, Germany). The APPJ was composed of a high-voltage power supply, a brush disperser (RBG 2000, Palas $\mathrm{GmbH}$, Karlsruhe, Germany), and a self-developed spray nozzle as an electrode. A cross-section of the electrode assembly group is shown in previous research [47].

To generate the plasma torch, an arc was ignited between the high voltage electrode and the grounded spraying nozzle, which was expelled using compressed air. The arc was ignited using a pulsed high voltage of $15 \mathrm{kV}$ (effective voltage 2-3 kV) and a pulse repetition frequency of $50 \mathrm{kHz}$ with a pulse period of 5-10 $\mu$ s. The input power of the APPJ was $2 \mathrm{~kW}$.

In the resulting plasma jet, bismuth oxide powder (grain size $<4 \mu \mathrm{m}$ ) (bismuth (III)-oxide, Asalco $\mathrm{GmbH}$, Lüneburg, Germany) was injected using compressed air via the brush disperser. The particles melted using the plasma werere deposited on borosilicate glass $\left(26 \times 76 \times 1 \mathrm{~mm}^{3}\right)\left(\mathrm{NEXTERION}^{\circledR}\right.$ glass B, SCHOTT Technical Glass Solutions GmbH, Jena, Germany), which traversed in meander-shaped paths a distance of $20 \mathrm{~mm}$ from the ground electrode.

The parameters that were changed for the experiments were plasma input power $\left(\mathrm{P}_{\mathrm{P}}\right)$, volumetric flow rate of the expelled air to generate the plasma torch $\left(\mathrm{q}_{\mathrm{P}}\right)$, traversing speed $(\mathrm{v})$, powder feed rate of the brush disperser $\left(\mathrm{q}_{\mathrm{D}}\right)$, and the feed speed of the disperser $\left(\mathrm{v}_{\mathrm{D}}\right)$; these parameters are displayed in Table 2. 
Table 2. Different coating parameters of the APPJ.

\begin{tabular}{cccccc}
\hline Sample No. & $\mathbf{P}_{\mathbf{P}}(\mathbf{\%})$ & $\mathbf{q}_{\mathbf{P}}(\mathbf{L} / \mathbf{m i n})$ & $\mathbf{v}(\mathbf{m m} / \mathbf{s})$ & $\mathbf{q}_{\mathbf{D}}\left(\mathbf{m}^{\mathbf{3}} \mathbf{h}\right)$ & $\mathbf{v}_{\mathbf{D}} \mathbf{( \mathbf { m m } / \mathbf { h } )}$ \\
\hline 1 & 80 & 30 & 100 & 2.2 & 50 \\
2 & 100 & 60 & 100 & 2.2 & 50 \\
3 & 100 & 30 & 40 & 2.2 & 50 \\
4 & 80 & 60 & 40 & 2.2 & 50 \\
5 & 80 & 60 & 100 & 4.3 & 50 \\
6 & 80 & 30 & 40 & 4.3 & 50 \\
7 & 100 & 30 & 100 & 4.3 & 50 \\
8 & 100 & 60 & 40 & 4.3 & 50 \\
9 & 100 & 60 & 40 & 2.2 & 100 \\
10 & 80 & 30 & 40 & 2.2 & 100 \\
11 & 100 & 30 & 100 & 2.2 & 100 \\
12 & 80 & 60 & 100 & 2.2 & 100 \\
13 & 100 & 30 & 40 & 4.3 & 100 \\
14 & 80 & 60 & 40 & 4.3 & 100 \\
15 & 100 & 60 & 100 & 4.3 & 100 \\
16 & 80 & 30 & 100 & 4.3 & 100 \\
\hline
\end{tabular}

\subsection{Characterization}

To determine the phase information, $\mathrm{X}$-ray diffraction $(\mathrm{XRD})$ diffractograms were measured using a Siemens D5000 diffractometer (Siemens AG, München, Germany) with $\mathrm{Cr}-\mathrm{K} \alpha$ radiation $(\lambda=2.28976 \AA$ ), operated in Bragg Brentano alignment at $30 \mathrm{~mA}$ and $40 \mathrm{kV}$ in the $2 \theta$ angular range of $30^{\circ}$ to $100^{\circ}$ with a scan interval of $0.02^{\circ}$ and $4.0 \mathrm{~s}$ per step. The diffraction patterns were calculated using the Rietveld refinement method [48] and refined using the GSAS-II software [49] (UChicago Argonne, LLC, Chicago, IL, USA).

The chemical surface composition was investigated using X-ray photoelectron spectroscopy (XPS) measurements on a PHI 5000 Versa Probe II (ULVAC-PHI, Osaka, Japan) using monochromatic Al-K $\alpha$ radiation with a photon energy of $1486.6 \mathrm{eV}$. The detector resolution measured at the $\mathrm{Ag} 3 d_{5 / 2}$ peak was $0.6 \mathrm{eV}$ at a pass energy of $23.5 \mathrm{eV}$. Detailed spectra of carbon (C 1s), oxygen (O 1s), bismuth (Bi 4f), and silicon (Si $2 p$ ) were recorded with a spot size of $200 \mu \mathrm{m}$, a pass energy of $46.95 \mathrm{eV}$, and a step size of $0.1 \mathrm{eV}$. To avoid charging effects, the measurements were carried out using neutralizing sample charging. All spectra were shifted to the main $\mathrm{C} 1$ s peak at $284.8 \mathrm{eV}$.

The UV-vis diffuse transmission spectra were recorded using a PerkinElmer 650 (PerkinElmer, Inc., Shelton, CT, USA) with an integrating sphere module in the range of 200-900 nm with a velocity of $10.5 \mathrm{~nm} / \mathrm{s}$ and a gap width of $5 \mathrm{~nm}$.

The layer thickness was determined using a laser scanning microscope (LSM) (VK-X100, KEYENCE Deutschland $\mathrm{GmbH}$, Neu-Isenburg, Germany) with a lens with 100× magnification.

\subsection{Photocatalytic Test}

The catalytic degradation tests were carried out in a self-developed reactor. In the metal surrounded-reactor, four internal $35 \mathrm{~W}$ xenon lamps were arranged $550 \mathrm{~mm}$ above the catalytic samples. The samples were placed in Petri dishes and filled with a pollutant solution of $25 \mathrm{~mL}$ distilled water, $245 \mu \mathrm{L}$ methyl orange ( $1 \mathrm{~g} / \mathrm{L}$ ) (MO) (AppliChem GmbH, Darmstadt, Germany), and $264 \mu \mathrm{L}$ ascorbic acid (200 g/L) (VWR International GmbH, Darmstadt, Germany). To ensure a permanent mixing of the liquids, the samples were mounted on a shaker. The degradation of the solution was measured using absorption spectroscopy of the pollutant solution depending on the irradiation time of 0-480 min with a TriStar² S LB 942 (BERTHOLD TECHNOLOGIES GmbH \& Co. KG, Bad Wildbad, Germany). 


\section{Conclusions}

In conclusion, it was shown that different amounts of crystal structures of tetragonal non-stoichiometric bismuth oxide and monoclinic bismuth oxide could be produced using an APPJ.

The amount of the different crystal phases was calculated using the Rietveld refinement method. The non-stoichiometric part of the oxide could be generated via the presence of nitrogen at the surface.

The XPS obtained data of the position of the bismuth and lattice oxygen peak showed a shift to higher binding energies as the non-stoichiometric phase fraction increased.

All FSs produced had a photon absorption of $2.64 \mathrm{eV}$ to $2.78 \mathrm{eV}$. The shift in the band gap could be explained by the loss of oxygen or the creation of oxygen vacancies at the surface, coating thickness, and the amount of crystal phases.

The degradation of methyl orange was shown in all samples during irradiation with xenon lamps. A conclusion on the photocatalytic efficiency due to phase fraction, band gap, or FS thickness was not possible. Only an influence of the LBEC could be shown. Further investigations, such as surface area using the Brunauer-Emmett-Teller (BET) method and photoluminescence emission spectroscopy could provide a conclusion to the photocatalytic degradation.

Author Contributions: Conceptualization, R.K.; Methodology, R.K., D.S. and L.K.; Validation, R.K., D.S., L.K., G.O. and W.V.; Investigation, R.K., D.S. and L.K.; Resources, G.O. and W.V.; Writing-Original Draft, R.K., D.S. and L.K.; Writing-Review and Editing, R.K., D.S., L.K., G.O. and W.V.

Funding: This research was funded by Bundesministerium für Bildung und Forschung (03XP0015A/B).

Acknowledgments: The authors thank the German Research Foundation (DFG) for the provision of the XPS. We thank Helmut Klein from the department of Crystallography, Georg-August-University of Goettingen, for support with the X-ray diffraction analysis.

Conflicts of Interest: The authors declare no conflict of interest.

\section{References}

1. Schlesinger, M.; Weber, M.; Schulze, S.; Hietschold, M.; Mehring, M. Metastable $\beta-\mathrm{Bi}_{2} \mathrm{O}_{3}$ Nanoparticles with Potential for Photocatalytic Water Purification Using Visible Light Irradiation. ChemistryOpen 2013, 2, 146-155. [CrossRef] [PubMed]

2. Drache, M.; Roussel, P.; Wignacourt, J.-P. Structures and oxide mobility in Bi-Ln-O materials: Heritage of $\mathrm{Bi}_{2} \mathrm{O}_{3}$. Chem. Rev. 2007, 107, 80-96. [CrossRef] [PubMed]

3. Ho, C.-H.; Chan, C.-H.; Huang, Y.-S.; Tien, L.-C.; Chao, L.-C. The study of optical band edge property of bismuth oxide nanowires $\alpha-\mathrm{Bi}_{2} \mathrm{O}_{3}$. Opt. Express 2013, 21, 11965-11972. [CrossRef] [PubMed]

4. Ambare, R.C.; Shinde, P.; Nakate, U.T.; Lokhande, B.J.; Mane, R.S. Sprayed bismuth oxide interconnected nanoplate supercapacitor electrode materials. Appl. Surf. Sci. 2018, 453, 214-219. [CrossRef]

5. Iljinas, A.; Burinskas, S.; Dudonis, J. Synthesis of Bismuth Oxide Thin Films Deposited by Reactive Magnetron Sputtering. Acta Phys. Pol. A 2011, 120, 60-62. [CrossRef]

6. Zhou, Y.; Dong, F.; Jin, S. (Eds.) Bismuth-Advanced Applications and Defects Characterization; IntechOpen Limited: London, UK, 2018; ISBN 978-1-78923-262-2.

7. Qiu, Y.; Yang, M.; Fan, H.; Zuo, Y.; Shao, Y.; Xu, Y.; Yang, X.; Yang, S. Nanowires of $\alpha-$ and $\beta-B_{2} \mathrm{O}_{3}$ : Phase-selective synthesis and application in photocatalysis. CrystEngComm 2011, 13, 1843-1850. [CrossRef]

8. Xu, Z.; Tabata, I.; Hirogaki, K.; Hisada, K.; Wang, T.; Wang, S.; Hori, T. Nontraditional template synthesis of microjagged bismuth oxide: A highly efficient visible light responsive photocatalyst. Catal. Sci. Technol. 2011, 1, 397-400. [CrossRef]

9. Oudghiri-Hassani, H.; Rakass, S.; Al Wadaani, F.T.; Al-ghamdi, K.J.; Omer, A.; Messali, M.; Abboudi, M. Synthesis, characterization and photocatalytic activity of $\alpha-\mathrm{Bi}_{2} \mathrm{O}_{3}$ nanoparticles. J. Taibah Univ. Sci. 2018, 9, 508-512. [CrossRef]

10. Iyyapushpam, S.; Nishanthi, S.T.; Pathinettam Padiyan, D. Synthesis of room temperature bismuth oxide and its photocatalytic activity. Mater. Lett. 2012, 86, 25-27. [CrossRef] 
11. Ratova, M.; Marcelino, R.; de Souza, P.; Amorim, C.; Kelly, P. Reactive Magnetron Sputter Deposition of Bismuth Tungstate Coatings for Water Treatment Applications under Natural Sunlight. Catalysts 2017, 7, 283. [CrossRef]

12. Yan, Y.; Zhou, Z.; Cheng, Y.; Qiu, L.; Gao, C.; Zhou, J. Template-free fabrication of $\alpha$ - and $\beta-B_{2} \mathrm{O}_{3}$ hollow spheres and their visible light photocatalytic activity for water purification. J. Alloy. Compd. 2014, 605, 102-108. [CrossRef]

13. Khan, M.M.; Adil, S.F.; Al-Mayouf, A. Metal oxides as photocatalysts. J. Saudi Chem. Soc. 2015, 19, 462-464. [CrossRef]

14. Liu, G.; Li, S.; Lu, Y.; Zhang, J.; Feng, Z.; Li, C. Controllable synthesis of $\alpha-\mathrm{Bi}_{2} \mathrm{O}_{3}$ and $\gamma-\mathrm{Bi}_{2} \mathrm{O}_{3}$ with high photocatalytic activity by $\alpha-\mathrm{Bi}_{2} \mathrm{O}_{3} \rightarrow \gamma-\mathrm{Bi}_{2} \mathrm{O}_{3} \rightarrow \alpha-\mathrm{Bi}_{2} \mathrm{O}_{3}$ transformation in a facile precipitation method. J. Alloy. Compd. 2016, 689, 787-799. [CrossRef]

15. Chen, R.; Shen, Z.-R.; Wang, H.; Zhou, H.-J.; Liu, Y.-P.; Ding, D.-T.; Chen, T.-H. Fabrication of mesh-like bismuth oxide single crystalline nanoflakes and their visible light photocatalytic activity. J. Alloy. Compd. 2011, 509, 2588-2596. [CrossRef]

16. Köhler, R.; Ohms, G.; Militz, H.; Viöl, W. Atmospheric Pressure Plasma Coating of Bismuth Oxide Circular Droplets. Coatings 2018, 8, 312. [CrossRef]

17. Ilschner, B.; Haefer, R.A. Oberflächen- und Dünnschicht-Technologie; Springer: Berlin/Heidelberg, Germany, 1987; ISBN 978-3-540-16723-5.

18. Medina, J.C.; Bizarro, M.; Gomez, C.L.; Depablos-Rivera, O.; Mirabal-Rojas, R.; Monroy, B.M.; Fonseca-Garcia, A.; Perez-Alvarez, J.; Rodil, S.E. Sputtered bismuth oxide thin films as a potential photocatalytic material. Catal. Today 2016, 266, 144-152. [CrossRef]

19. Kumari, L.; Lin, J.-H.; Ma, Y.-R. One-dimensional Bi(2)O(3) nanohooks: Synthesis, characterization and optical properties. J. Phys. Condens. Matter 2007, 19, 406204. [CrossRef] [PubMed]

20. Uchida, K.; Ayame, A. Dynamic XPS measurements on bismuth molybdate surfaces. Surf. Sci. 1996, 357-358, 170-175. [CrossRef]

21. Zhang, X.; Qin, J.; Xue, Y.; Yu, P.; Zhang, B.; Wang, L.; Liu, R. Effect of aspect ratio and surface defects on the photocatalytic activity of ZnO nanorods. Sci. Rep. 2014, 4, 4596. [CrossRef] [PubMed]

22. Ishfaq, M.; Rizwan Khan, M.; Bhopal, M.F.; Nasim, F.; Ali, A.; Bhatti, A.S.; Ahmed, I.; Bhardwaj, S.; Cepek, C. $1.5 \mathrm{MeV}$ proton irradiation effects on electrical and structural properties of TiO2/n-Si interface. J. Appl. Phys. 2014, 115, 174506. [CrossRef]

23. Ansari, S.A.; Khan, M.M.; Ansari, M.O.; Kalathil, S.; Lee, J.; Cho, M.H. Band gap engineering of CeO2 nanostructure using an electrochemically active biofilm for visible light applications. RSC Adv. 2014, 4, 16782-16791. [CrossRef]

24. Dharmadhikari, V.S.; Sainkar, S.R.; Badrinarayan, S.; Goswami, A. Characterisation of thin films of bismuth oxide by X-ray photoelectron spectroscopy. J. Electron Spectrosc. Relat. Phenom. 1982, 25, 181-189. [CrossRef]

25. Wittstock, G.; Strübing, A.; Szargan, R.; Werner, G. Glucose oxidation at bismuth-modified platinum electrodes. J. Electroanal. Chem. 1998, 444, 61-73. [CrossRef]

26. Abdullah, E.A.; Abdullah, A.H.; Zainal, Z.; Hussein, M.Z.; Ban, T.K. Bismuth Basic Nitrate as a Novel Adsorbent for Azo Dye Removal. E-J. Chem. 2012, 9, 1885-1896. [CrossRef]

27. Yang, S.Y.; Liu, L.; Jia, Z.X.; Fu, W.W.; Jia, D.M.; Luo, Y.F. Study on the structure-properties relationship of natural rubber/SiO2 composites modified by a novel multi-functional rubber agent. Express Polym. Lett. 2014, 8, 425-435. [CrossRef]

28. Alessio Verni, G.; Long, B.; Gity, F.; Lanius, M.; Schüffelgen, P.; Mussler, G.; Grützmacher, D.; Greer, J.; Holmes, J.D. Oxide removal and stabilization of bismuth thin films through chemically bound thiol layers. Rsc Adv. 2018, 8, 33368-33373. [CrossRef]

29. Barrera-Mota, K.; Bizarro, M.; Castellino, M.; Tagliaferro, A.; Hernández, A.; Rodil, S.E. Spray deposited $\beta-\mathrm{Bi}_{2} \mathrm{O}_{3}$ nanostructured films with visible photocatalytic activity for solar water treatment. Photochem. Photobiol. Sci. 2015, 14, 1110-1119. [CrossRef]

30. Xu, J.-J.; Chen, M.-D.; Fu, D.-G. Preparation of bismuth oxide/titania composite particles and their photocatalytic activity to degradation of 4-chlorophenol. Trans. Nonferrous Met. Soc. China 2011, 21, 340-345. [CrossRef]

31. Liu, Y.; Wang, Z.; Huang, B.; Zhang, X.; Qin, X.; Dai, Y. Enhanced photocatalytic degradation of organic pollutants over basic bismuth (III) nitrate/BiVO4 composite. J. Colloid Interface Sci. 2010, 348, 211-215. [CrossRef] 
32. Cheng, H.; Huang, B.; Lu, J.; Wang, Z.; Xu, B.; Qin, X.; Zhang, X.; Dai, Y. Synergistic effect of crystal and electronic structures on the visible-light-driven photocatalytic performances of $\mathrm{Bi}(2) \mathrm{O}(3)$ polymorphs. Phys. Chem. Chem. Phys. 2010, 12, 15468-15475. [CrossRef]

33. Sun, Y.; Zhang, Z.; Xie, A.; Xiao, C.; Li, S.; Huang, F.; Shen, Y. An ordered and porous N-doped carbon dot-sensitized $\mathrm{Bi}_{2} \mathrm{O}_{3}$ inverse opal with enhanced photoelectrochemical performance and photocatalytic activity. Nanoscale 2015, 7, 13974-13980. [CrossRef] [PubMed]

34. Wang, Y.; Jiang, L.; Chen, J.; Liu, F.; Lai, Y. Realization of nanostructured N-doped p-type $\mathrm{Bi}_{2} \mathrm{O}_{3}$ thin films. Mater. Lett. 2017, 193, 228-231. [CrossRef]

35. Hajra, P.; Shyamal, S.; Mandal, H.; Sariket, D.; Maity, A.; Kundu, S.; Bhattacharya, C. Synthesis of oxygen deficient bismuth oxide photocatalyst for improved photoelectrochemical applications. Electrochim. Acta 2019, 299, 357-365. [CrossRef]

36. Yang, X.; Lian, X.; Liu, S.; Jiang, C.; Tian, J.; Wang, G.; Chen, J.; Wang, R. Visible light photoelectrochemical properties of $\beta-\mathrm{Bi}_{2} \mathrm{O}_{3}$ nanoporous films: A study of the dependence on thermal treatment and film thickness. Appl. Surf. Sci. 2013, 282, 538-543. [CrossRef]

37. Akaltun, Y.; Yıldırım, M.A.; Ateş, A.; Yıldırım, M. The relationship between refractive index-energy gap and the film thickness effect on the characteristic parameters of CdSe thin films. Opt. Commun. 2011, 284, 2307-2311. [CrossRef]

38. Selvamani, T.; Anandan, S.; Granone, L.; Bahnemann, D.W.; Ashokkumar, M. Phase-controlled synthesis of bismuth oxide polymorphs for photocatalytic applications. Mater. Chem. Front. 2018, 2, 1664-1673. [CrossRef]

39. Sirota, B.; Reyes-Cuellar, J.; Kohli, P.; Wang, L.; McCarroll, M.E.; Aouadi, S.M. Bismuth oxide photocatalytic nanostructures produced by magnetron sputtering deposition. Thin Solid Films 2012, 520, 6118-6123. [CrossRef]

40. Iyyapushpam, S.; Nishanthi, S.T.; Pathinettam Padiyan, D. Enhanced photocatalytic degradation of methyl orange by gamma $\mathrm{Bi}_{2} \mathrm{O}_{3}$ and its kinetics. J. Alloy. Compd. 2014, 601, 85-87. [CrossRef]

41. Gujar, T.P.; Shinde, V.R.; Lokhande, C.D. The influence of oxidation temperature on structural, optical and electrical properties of thermally oxidized bismuth oxide films. Appl. Surf. Sci. 2008, 254, 4186-4190. [CrossRef]

42. Salim, E.T.; Al-Douri, Y.; Al Wazny, M.S.; Fakhri, M.A. Optical properties of Cauliflower-like $\mathrm{Bi}_{2} \mathrm{O}_{3}$ nanostructures by reactive pulsed laser deposition (PLD) technique. Sol. Energy 2014, 107, 523-529. [CrossRef]

43. Iljinas, A.; Marcinauskas, L. Formation of bismuth oxide nanostructures by reactive plasma assisted thermal evaporation. Thin Solid Films 2015, 594, 192-196. [CrossRef]

44. Al-Kahtani, A.A. Photocatalytic Degradation of Rhodamine B Dye in Wastewater Using Gelatin/CuS/PVA Nanocomposites under Solar Light Irradiation. J. Biomater. Nanobiotechnol. 2017, 8, 66-82. [CrossRef]

45. Hou, J.; Yang, C.; Wang, Z.; Zhou, W.; Jiao, S.; Zhu, H. In situ synthesis of $\alpha-\beta$ phase heterojunction on $\mathrm{Bi}_{2} \mathrm{O}_{3}$ nanowires with exceptional visible-light photocatalytic performance. Appl. Catal. B Environ. 2013, 142-143, 504-511. [CrossRef]

46. Iyyapushpam, S.; Nishanthi, S.T.; Pathinettam Padiyan, D. Photocatalytic degradation of methyl orange using $\alpha-\mathrm{Bi}_{2} \mathrm{O}_{3}$ prepared without surfactant. J. Alloy. Compd. 2013, 563, 104-107. [CrossRef]

47. Wallenhorst, L.M.; Loewenthal, L.; Avramidis, G.; Gerhard, C.; Militz, H.; Ohms, G.; Viöl, W. Topographic, optical and chemical properties of zinc particle coatings deposited by means of atmospheric pressure plasma. Appl. Surf. Sci. 2017, 410, 485-493. [CrossRef]

48. Rietveld, H.M. A profile refinement method for nuclear and magnetic structures. J. Appl. Crystallogr. 1969, 2, 65-71. [CrossRef]

49. Toby, B.H.; von Dreele, R.B. GSAS-II: The genesis of a modern open-source all purpose crystallography software package. J. Appl. Crystallogr. 2013, 46, 544-549. [CrossRef]

(C) 2019 by the authors. Licensee MDPI, Basel, Switzerland. This article is an open access article distributed under the terms and conditions of the Creative Commons Attribution (CC BY) license (http://creativecommons.org/licenses/by/4.0/). 